\title{
A DEDICATION TO ARTEMIS
}

THE coin of Sicyon, of the obverse of which a drawing by Mr. F. Anderson (made over a photograph) is given here, has been twice published both times by Professor Percy Gardner. ${ }^{1}$

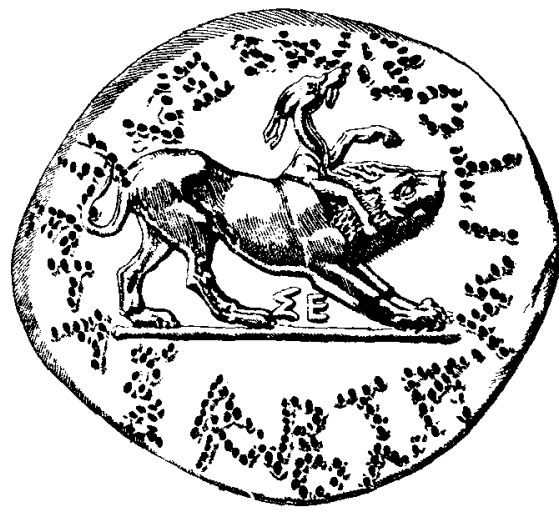

Stater of Sicyon (British Museum). Enlarged 2 diameters.

It is a stater of the fourth century B.C., of the usual types :

Obverse: ¿E Chimaera to $\mathrm{r}$.

Reverse: Dove flying r.; behind it, over the tail, a small bow. The whole in an olive-wreath. Concave field. Slightly doublestruck on both sides.

Weight 188 grains (12:182 grammes).

The inscription on the obverse, which lends special interest to this piece, is unique among adscititious inscriptions upon Greek coins, ${ }^{2}$ not only in its elaborate character, but in the manner of its execution. Such inscriptions are in other cases graffiti, scratched with a point; this is pricked into the metal with a pointed instrument.

\footnotetext{
1 Numismatic Chronicle, 1873, p. 183 (Pl. Revue Numism. 1874-77, pp. 325 f. To his VII. Fig. 5, from a drawing by F. Lees) ; Brit. list add the coins of Pheneus, J.H.S. xvii. p. 83, Mus. Catal. Peloponnesus, p. 41, no. 65, (P1. and Corinth, Rev. Num. 1898, p. xliii. and VII. 26, autotype).

and Corinth, Rev. Num. 1898, p. x
B. M. Catal. Corinth, nos. 8, 131, 226.
}

2 They have been collected by F. Lenormant, 
Professor Gardner, in publishing the inscription, reads it

\section{APTAMITOE TAE EAKETAE AMON.}

He adds that the $T$ of the third word may be a $\Gamma$, the $A$ of the fourth word is indistinct, and that 'at the end of that word is a mark which might stand for 1 , although I believe it merely to indicate the end of the inscription, there being a similar mark at the end of the first word.' These difficulties are, however, small in comparison with that connected with the meaning of

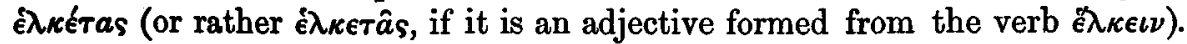
None of the explanations connecting the word with $\ddot{e} \lambda \kappa \epsilon \iota \nu$ seems to me entirely satisfactory. ${ }^{1}$

Under these circumstances a further examination of the inscription seemed worth the making. My results are as follows.

In the first place, as will be seen from the drawing, the initial letter of the inscription is most probably that which stands under the chimaera's tail, behind the left hind leg. I make no doubt that the letter is $T$ and not $\Gamma$, which could hardly be represented with the same number of points in both strokes, even in a carelessly punctured inscription (which this is not). But if it is $\mathrm{T}$, its position in regard to the other letters can only be explained by its being the first letter of the inscription. In beginning the dedication, it was natural to hold the coin so that the type stood the right way up. But the writer found out his mistake when he came to make the second letter. If on the other hand this $T$ is not the first letter in the inscription, its position is much less explicable.

The inscription offers no further difficulty until we come to the first letter of the second (outer) circle. This is read by Mr. Gardner as A. All that is visible is $\Delta$. It might be supposed that the lower parts of the two legs of A were omitted owing to want of room. But this supposition is excluded by the fact that in other cases of confined space the punctures are carried over the edge of the coin, as may be plainly seen in the letters KE behind the tail of the chimaera. Hence there seems little doubt that the letter in question is $\Delta$ and not $A$.

After the letter $\mathrm{N}$ comes the last sign in the inscription; Mr. Gardner conjectures this to be a stop of the same kind as occurs at the close of the word ARTAMITOE. But while the latter stop is made with two strokes of the instrument, effecting marks much larger than any others in the inscription, the sign at the end is made in exactly the same way as the letters. It is safe, therefore, to suppose it to be $I$ and not a stop.

Thus read, the inscription becomes

\section{TAEARTAMITOETAEEAKE $\triangle M O N I$}

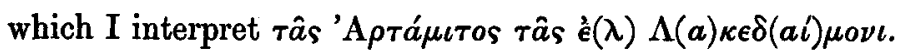

1 'Drawer of the bow,' 'deliverer from trouble,' 'helper in childbirth.' It is also questionable whether i $\lambda_{\kappa \in \tau} \delta$ s is a possible formation; and the termination -ros would at any rate have a passive force. 
The omission of the second letter of the preposition is of course quite in

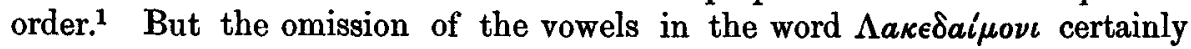
gives pause. The first A could, however, easily escape, owing to the $\wedge$ immediately preceding it; the Al must have been sacrificed for reasons of space. It was more necessary to preserve the dative termination than the vowels in the middle of the word. ${ }^{2}$

Abbreviation by syncope is excessively rare in Greek before Byzantine times. $^{3}$ As M. Perdrizet has shown, ${ }^{4} \beta a \lambda$ éos on the now famous tile of King Nabis is not an abbreviation, but an imperfect rendering of the rapid pronunciation of the Doric form $\beta a h \imath \lambda$ éos as $\beta a h \lambda \lambda^{\prime}$ s. But the form $\beta a v s$ which occurs on tetradrachms of Smyrna ${ }^{5}$ at the beginning of the second century B.c. is an undoubted instance of syncopated abbreviation. The form $\beta a \sigma \sigma \eta s$ has been quoted from a papyrus of the time of Euergetes II., ${ }^{6}$ but it is so carelessly written that it can hardly count as evidence. ${ }^{7}$

On Greek coins of the Imperial period, especially at the beginning of third century, it is common to find the word AYTOKPAT $\Omega$ P abbreviated AYTKP or AYTKPA. ${ }^{8}$ This form occurs so often that it can hardly be due to a mere blunder. In the $C B$ which is sometimes found instead of $C \in B(a \sigma \tau o ́ s)$, the loss of the $€$ may perhaps be explained by its likeness to $C$.

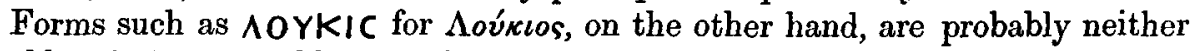
abbreviations nor blunders, but, like HMIOBEAIN, anticipations of the later Greek terminations $-\iota \varsigma,-\iota \nu .^{9}$ After the $\beta a v s$ of the coins of Smyrna, the earliest instance of syncopated abbreviation known to me in official inscrip-

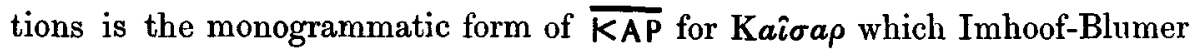
has described from coins of Chalcedon and Byzantium struck at the beginning of the Empire. ${ }^{10}$ But many methods might have been allowed in monograms which were unusual in ordinary writing.

These notes are sufficient to show that the syncopated method of abbreviation existed, though sporadically, at an earlier period than is generally supposed.

1 Cp. $\operatorname{\tau oi}(\lambda) \Lambda a s e \delta a \iota \mu o v i o[ı s]$ (undoubtedly the right restoration) Olympia Inschr. 252. In other cases the double $\lambda$ is written : $\dot{\epsilon} \lambda$ $\Lambda \alpha \kappa \in \delta a i^{-}$

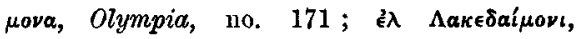
Meister, Gr. Dial.- Inschriften, 4430. But its omission is in accordance with the rule which

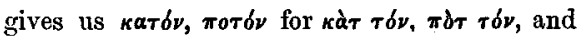
other single writings of double letters.

2 In APTAMTS, which occurs in an in. scription on a metal vessel (Hoffmann, Gr. Dial.-Inschr. 1600; Purgold, Arch. Zeitung xl. (1882) p. 393 ), the first $S$ is probably omitted by a mere accident. The epithet preceding should perhaps be completed $[A \mid C]$ EPATS; for the worship of Artemis at Aigeira see Paus. vii. $26.2 \mathrm{f}$.

${ }^{3}$ No instances are given by J. Simon, Abkïr. zungen auf gr. Inschr. in the Zeitschr. $f . d$. österreich. Gymnasien, 1891, p. $673 \mathrm{ff}$. For a form like KN for Kuv6roupa (p. 709), even if the restoration were certain, would hardly count.

${ }^{4}$ Numism. Chron. 1898, p. 5.

5 E.g. Mionnet, iii. p. 190, no. 917 ; Supp. vi. p. 302 , no. 1391 .

6 Grenfell, An Alexandrian Erotic Fragment etc., no. 24.

7 Mr. Kenyon points out that there is roon for more than $\sigma \sigma$, and that the word appears to be $\beta a \sigma \iota \lambda i \sigma \sigma \eta s$ very cursively written.

8 E.g. at Perinthus, Berlin Beschr. d. ant. Jiüzen, i. p. 214, nos. 41, 43.

9 J.H.S. 1897 , p. 82 ; Jannaris, Historicel Greek Grammar, $\$ 301,302$.

10 Joumal International d'Arch. Numism. i. (1898), pp. 15 f. 
It remains only to admit that it is impossible to ascertain to which of the many goddesses named Artemis in Lacedaemon this coin of Sicyon was dedicated. If, however, the dedication was pricked on the coin before the worshipper came to Lacedaemon, the want of closer definition does not seem unnatural. ${ }^{1}$

Since the above remarks were put into type, the inscription with which they are concerned has been interpreted in yet another way by Professor $O$. Rossbach. ${ }^{2}$ In most of the preliminaries to an explanation we are agreed; as, for instance, in the identification of the initial letter, and in the interpretation of the final word as a dative. The 17 th letter, however, he takes to be $\boldsymbol{\gamma}$, and his transliteration is accordingly

\section{Tâs 'A}

This interpretation has the one great advantage of dispensing with the abbreviation which I have assumed. On the other hand, two considerations lead me to adhere to the interpretation I have proposed. In the first place, as Prof. Rossbach himself admits, the place-name $K \epsilon \delta \mu \omega \nu$ is entirely unknown. The invention of this name is not entirely justified by any philological probability it may possess, or by the addition it makes to our list of sanctuaries of Artemis. Secondly, the form $\wedge$ for $\gamma$, although by no means impossible in Peloponnesian alphabets, is much less common than $\Gamma$. The probabilities are therefore in favour of the value which has hitherto been given to the sign in this inscription.

G. F. HrLL.

\footnotetext{
1 At the shrine of Zeus Kasios in Corcyra a stamp with the name of the god, $\Delta i \delta$ s (monogrammstically written) Kaolo, was impressed on dedicated coins (Brit. Mus. Catal. Thessaly to Letotia, p. 158 , nos. 615-632, including coins
}

of Lacedaemon and Cnidus, as well as of Corcyra
itself). It would seem that the stamp in this
case was provided by the temple anthorities.
2 Berliner Philolog. Wochenschrift, 20 Aug.
1898 , p. 1053 . 